\title{
The Forgotten Lateral Approach to the Upper Cervical Spine, Case Report
}

\author{
S Georgiev*, S Calero-Martinez, P Fistouris and U Schick \\ Department of Neurosurgery, Academic Hospital of Muenster University, Germany \\ *Corresponding author: S Georgiev, Department of Neurosurgery, Clemens Hospital, Academic Hospital of Muenster University, Muenster, Germany
}

Submission: April 27, 2018; Published: May 29, 2018

\begin{abstract}
We present a case of a 73-year old female with a giant spinal cord schwannoma WHO grade I at the level of C2/3. We performed the rare lateral approach to the upper spine, a forgotten invasive procedure modified by us for better tumor exposure. The tumor was removed completely with rapid neurological improvement. .
\end{abstract}

Keywords: Schwannoma; Lateral approach; Upper cervical spine

\section{Introduction}

Lesions which are ventral or ventrolateral to the spinal cord in the upper cervical spine present technical problems in removal. The anterior approach to the cervical spine is useful to manage intervertebral disc disease and vertebral body tumors. Transoral approaches are in general left because of the morbidity and the complications. Extraoral approaches to the upper cervical spine provide a limited exposure to the intradural space [1,2]. The posterior approach is chosen for lesions displacing the spinal cord laterally.

We are presenting a lateral approach to the upper cervical spine which allows perfect view of the ventro-lateral and lateral parts of the vertebral canal. This is a modification of an operation described by Shucart for exposure of a dorso-lateral lesion extending from C-3 to the foramen magnum [1].

\section{Case Report}

A 73-year old female patient was admitted to neurosurgery with a history of chronic cervicobrachial pain that radiates to the right-hand side. The patient complained also about difficulties in writing. The symptoms started almost one and half year ago. At the time of admission, the patient had difficulties in standing and walking alone. The clinical and neurologic examination revealed radicular pain in the right arm, hypaesthesia on the right side of the body, weakness in the right leg, increased muscle reflexes on the lower extremities and pronounced ataxia.
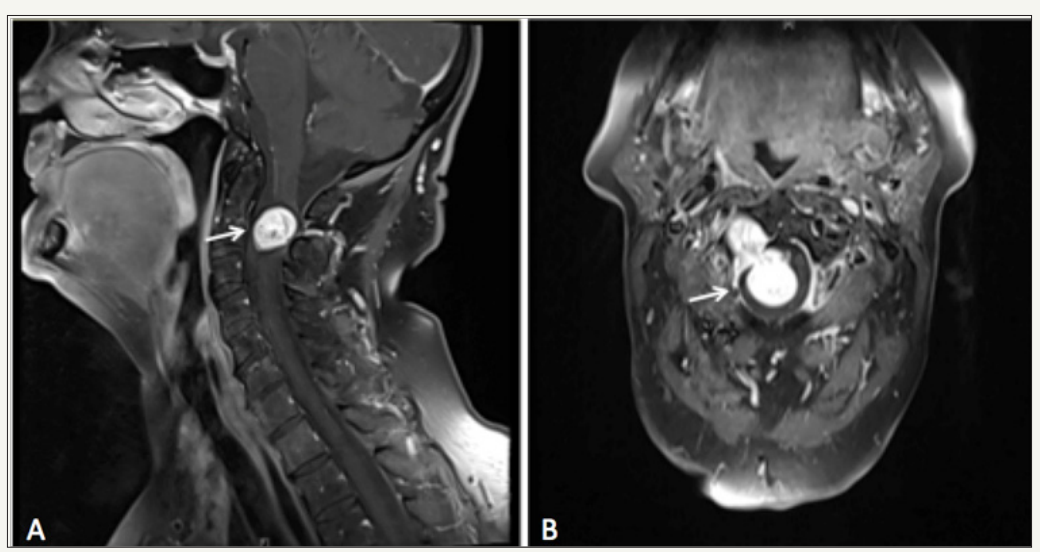

Figure 1: Preoperative contrast MRI of the cervical spine A- sagittal view, B- coronal view showing typical intra-extradural and dumbbell-shaped mass at the level of $\mathrm{C} 2-\mathrm{C} 3$ vertebrae. 
The MRI revealed a 15 x $30 \mathrm{~mm}$ contrast-enhanced mass located at the level of C2-C3 vertebrae (Figure 1). The lesion caused a severe displacement of the cord to the left side. The CT with CTangiography revealed the expanded neuroforamen $\mathrm{C} 2 / 3$ on the right side and the shift of the vertebral artery (VA) Figure 2.

\section{Surgical Procedure}

We performed a lateral incision behind the sternocleidomastoid muscle (SCM), an almost forgotten approach to the upper cervical spine (Figure 3).

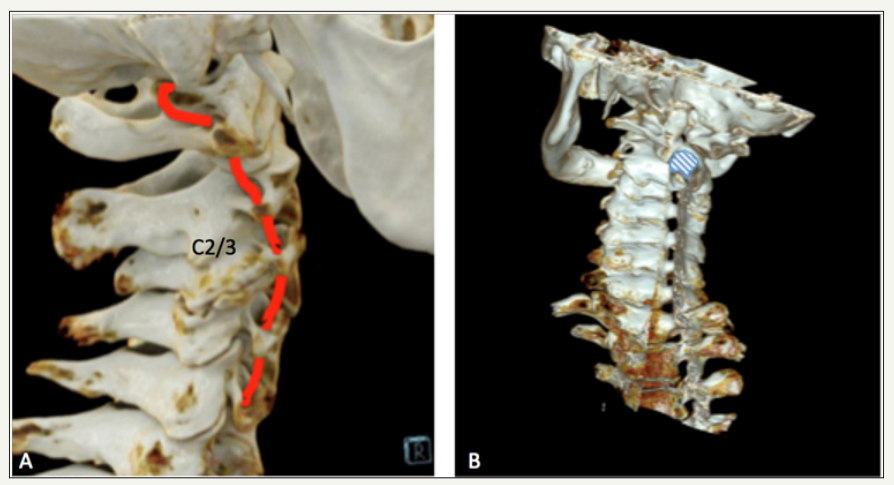

Figure 2: Three-dimensional reconstruction computed tomography of cervical spine showing the right vertebral artery and the $\mathrm{C} 2 / 3$ facet joint on the right side (A) and expanded neuroforamen $\mathrm{C} 2 / 3$ on the right side (B).
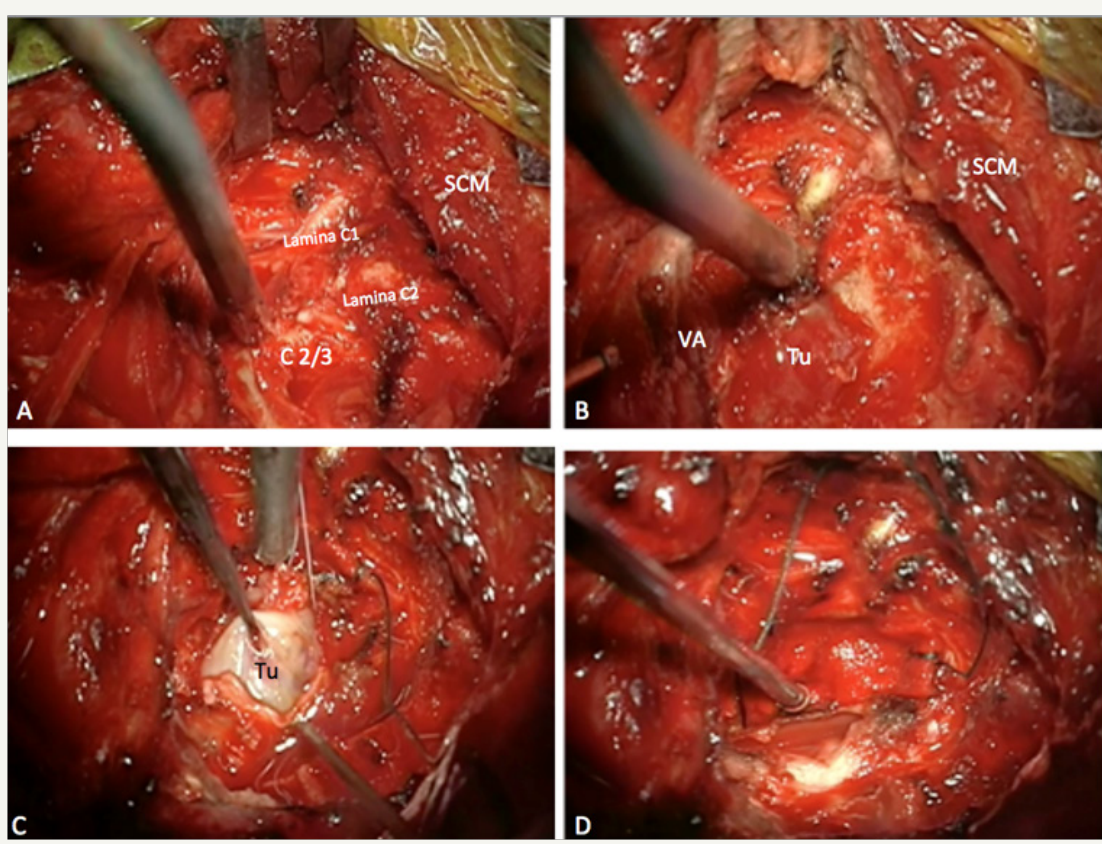

Figure 3: Intraoperative view. A. C2/3 facet joint on the right side, SCM- sternocleidomastoid muscle; B- VA- vertebral artery, Tu- tumor; C. Schwannoma inside the dura; D. gross total resection of the tumor.

Under general anesthesia the patient is placed in left lateral position. The head is slightly anteflexed, tilted to the left and fixed in the Mayfield head-clamp. The skin incision is made along the rear border of the SCM with extension along the inferior nuchal line. The platysma muscle is divided, and the sternocleidomastoid and the trapezius muscles are mobilized until the occipital minor nerve is exposed. The nerve is mobilized laterally. The splenius capitis muscle is mobilized dorsally and the SCM ventrally. Subsequently the transverse process of $\mathrm{C} 1$ could be exposed. The inferior and superior root of ansacervicalis was exposed and preserved superiorly.
The facet joints of $\mathrm{C} 1 / 2$ and $\mathrm{C} 2 / 3$ are then seen and the lamina of C2 and C3 can be identified. At this point the vertebral artery (VA) can be seen between the transverse processes C1 and C2. After cutting the $\mathrm{C} 3$ root, the tumor could be exposed. For better view of the tumor, the $\mathrm{C} 2$-lamina and the facet joint $\mathrm{C} 2 / 3$ should be removed. The tumor was completely removed, with the vertebral artery carefully protected in the extradural part. The vertebral artery was detected using intraoperative doppler flow. The second step starts intraspinal, desiccating the tumor in all directions. The dura was opened in the middle, then the tumor was removed carefully with the CUSA without complications. During the whole 
procedure neuromonitoring with MEPs and SSEPs was performed. After tumor removal the SSEPs accelerated $2 \mathrm{msec}$. The dura was closed with a dural graft and covered with fat and fibrine glue.

\section{Postoperative Course}

After the operation the patient had a pain overlaid muscle elevation weakness of the right arm, which has improved within 3 weeks. There was no evidence of postoperative spinal cord trauma or new neurological deficits. The patient was completely mobilized. A ventral cage fusion and plate osteosynthesis were performed to stabilize the cervical spine. The follow-up MRI and CT of the cervical spine showed the complete removal of the tumor (Figure 4).
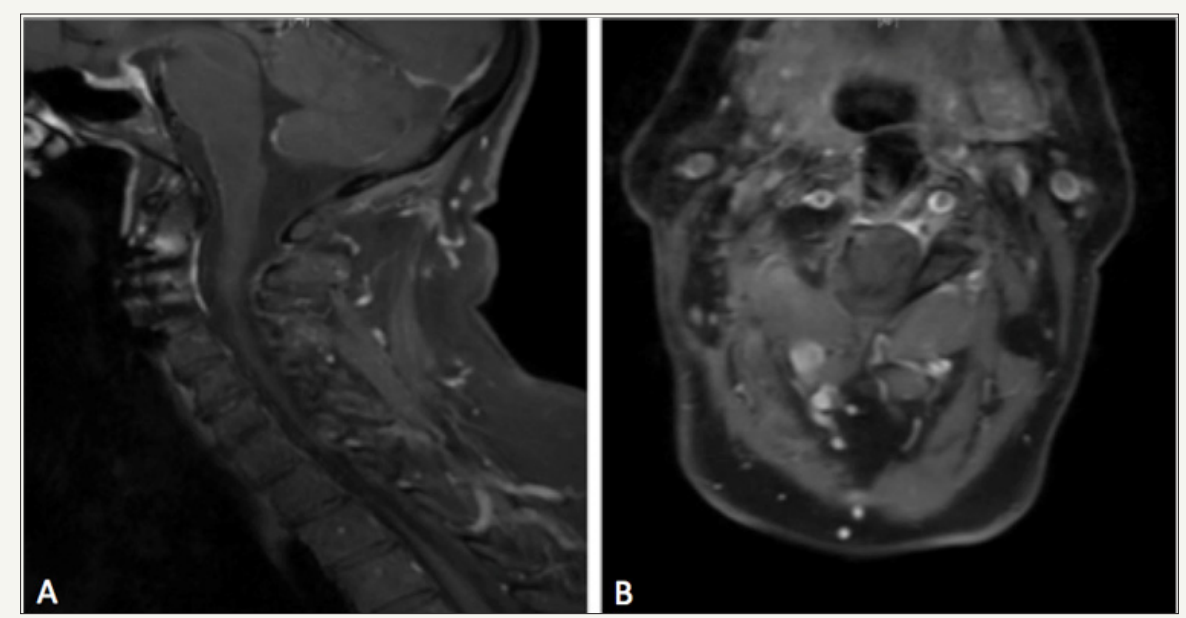

Figure 4: Postsurgery contrast MRI of the cervical spine A- sagittal view, B- coronal view confirms gross total resection of the tumor, without hematoma or recurrence.

\section{Discussion}

Surgical approaches for spinal schwannoma resection is the preferred treatment option. Usually a dorsal approach will be performed to reach the tumors of the upper cervical spine $[4,5]$. We have performed the forgotten lateral approach to the upper cervical spine. This approach provides a better exposure of the lateral and ventral portions of the spinal canal and is very useful for lesions between foramen magnum and C-3. Better outcomes have been also described by using intraoperative neuromonitoring. The extent of the bone removal is comparable to the bone removal of the posterior approach. The cervical spine remains stable if the joints are not disturbed from the tumor [1]. This approach requires no spinal cord retraction for ventrolateral lesions.

The development of the IOM has minimized postsurgical neurological complication [3]. The lateral approach presented here provides an excellent exposure of the lateral and ventral portions of the C1, C2 and C3 including the vertebral artery. Potential complications with this approach include injury to the spinal accessory nerve and the vertebral artery. The accessory nerve and jugular vein which are running together can be identified early. The spinal accessory nerve is more likely to be injured during retraction by stretching. Another important anatomical landmark is the vertebral artery. For better assessment of the vertebral artery
CT angiography is recommended preoperatively. This approach offers the best trajectory for tumor removal without further spinal cord compression. Anatomical knowledge is crucial. After the tumor removal, attention should be paid for spinal instability, if it presents, it should be stabilized [6].

\section{References}

1. Shucart WA, Kleriga E (1980) Lateral approach to the upper cervical spine. Neurosurgery 6(3): 278-281.

2. Sen CN, Sekhar LN (1990) An extreme lateral approach to the intradural lesions of the cervical spine and foramen magnum. Neurosurgery 27(2): 197-204.

3. Thirumala PD, Muralidharan A, Loke YK, Habeych M, Crammond D, et al. (2016) Value of intraoperative neurophysiological monitoring to reduce neurological complications in patients undergoing anterior cervical spine procedures for cervical spondylotic myelopathy. J Clin Neurosci 25: 27-35.

4. McCormick PC (1996) Surgical management of dumbbell tumors of the cervical spine. Neurosurgery 38(2): 294-300.

5. Kyoshima K, Uehara T, Koyama J, Idomari K, Yomo S (2003) Dumbbell C2 schwannomas involving both sensory and motor rootlets: Report of two cases. Neurosurgery 53(2): 436-440.

6. Goel A, Muzumdar D, Nadkarni T, Desai K, Dange N, et al. (2008) Retrospective analysis of peripheral nerve sheath tumors of the second cervical nerve root in 60 surgically treated patients. J Neurosurg Spine 8(2): 129-134. 

(c) (i) Creative Commons Attribution 4.0

For possible submissions Click Here

Submit Article

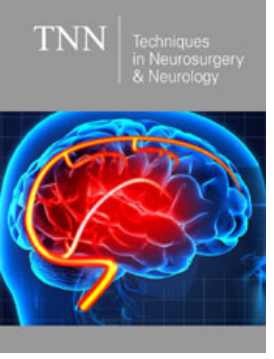

\section{Techniques in Neurosurgery \& Neurology}

\section{Benefits of Publishing with us}

- High-level peer review and editorial services

- Freely accessible online immediately upon publication

- Authors retain the copyright to their work

- Licensing it under a Creative Commons license

- Visibility through different online platforms 